\title{
Caracterização fúngica e formação de biofilme em éguas com endometrite
}

Fungal characterization and biofilm formation in mares with endometritis

\author{
José Adelson Alves do Nascimento Júnior ${ }^{1}$, Emanuel Felipe de Oliveira Filho ${ }^{2}$, Aldo Gimendis \\ Pereira de Melo $^{2}$, Maria Tereza dos Santos Correia ${ }^{1}$, Gustavo Ferrer Carneiro ${ }^{2}$ \\ ${ }^{1}$ Universidade Federal de Pernambuco - UFPE, Recife, PE Brasil \\ ${ }^{2}$ Universidade Federal Rural de Pernambuco - UFRPE, Departamento de Medicina Veterinária-DMV \\ Rua Dom Manoel de Medeiros, S/N, Dois Irmãos, Recife-PE, Brasil
}

\begin{abstract}
Resumo
A endometrite é a principal causa de infertilidade em éguas, além de gerar grandes transtornos econômicos e produtivos. Objetivou-se caracterizar a citologia, cultura bacteriana e fúngica, além da identificação da formação de biofilme em éguas com endometrite. Amostras de 70 éguas foram coletadas para citologia uterina e exame microbiológico. A determinação da formação de biofilme foi realizada através da técnica de cristal violeta. Das 70 éguas diagnosticadas com endometrite $43(61,4 \%)$ apresentaram infecção bacteriana e/ou fúngica. Das 43 éguas, 30,2\% (13/43) apresentaram infecção fúngica, os mais evidenciados foram Aspergillus spp. e Candida albicans, Curvalaria spp., Cladosporium spp. e Zygomices spp. Dos fungos identificados, 9/13 (69,2\%) formaram biofilme. Esses resultados revelam números de infecção fúngica acima da média em comparação com a literatura. Várias causas são reportadas ao aumento dos casos de endometrite fúngica, dentre elas o aumento no uso das biotecnologias reprodutivas provocando um excesso de manipulação uterina. É de suma importância a identificação do agente, o conhecimento da suscetibilidade farmacológica e a comprovação da produção de biofilme em casos de endometrite. Estas ferramentas podem fornecer subsídios ainda mais importantes para melhorar a eficiência reprodutiva e sanitária dos rebanhos equinos.
\end{abstract}

Palavras-chave: equino, bactéria, biofilme, endometrite, fungo

\section{Abstract}

Endometritis is the main cause of infertility in mares, besides generating major economic and productive disorders. The objective was to characterize the cytology, microbiological and fungal culture, as well as the identification of biofilm formation in mares with endometritis. Samples of seventy mares were collected for uterine cytology and microbiological examination. The determination of biofilm formation was performed using violet crystal technique. Of the seventy mares diagnosed with endometritis 43 (61.4\%) presented bacterial and/or fungal infection. From the 43 mares, 30.2\% (13/43) presented fungal infection, the most evidenced were Aspergillus spp. and Candida albicans, Curvalaria spp., Cladosporium spp. and Zygomices spp. Of the identified fungi, 9/13 (69.2\%) formed biofilm. These results reveal above average numbers of fungal infection compared to the literature. Several causes are related to the increase in cases of fungal endometritis, among them the increase in the use of reproductive biotechnologies, causing an excessive uterine manipulation. Identification of the agent, knowledge of pharmacological susceptibility and evidence of biofilm production in endometritis cases are extremely important. These tools can provide even more important subsidies to improve the reproductive and sanitary efficiency of equine herds.

Keywords: equine, bacterium, biofilm, endometritis, fungus

\section{Introdução}

A espécie equina possui várias particularidades em comparação a outras espécies. Com relação a características reprodutivas, na maioria das espécies domésticas o sêmen é depositado na vagina e os espermatozoides se direcionam ao útero. Já nos equinos devido às peculiaridades anatômicas da cérvice, os espermatozoides e demais componentes do sêmen são depositados no interior do útero. Este fato, torna a ocorrência das endometrites tão comuns (Traub-Dargatz et al., 1991).

${ }^{1}$ Correspondência: carneirogustavo1@gmail.com

Recebido: 16 de dezembro de 2019

Aceito: 01 de março de 2021 
A endometrite é uma inflamação do endométrio que pode ser caracterizada de forma aguda, crônica, crônica degenerativa ou até induzida pós-cobertura. As endometrites são uma das principais causas de infertilidade na espécie e reprodução equina (Leblanc, 2010). Esta enfermidade surge devido a contaminação do aparelho reprodutivo por microrganismos, em especial os bacterianos, considerados em sua maior parte como agentes patogênicos oportunistas (Wittenbrink, 2012), porém alguns fungos podem ser potencialmente patogênicos (Carneiro et al, 2019). A enfermidade pode ainda estar associadas a fatores ligados a falhas nos mecanismos de defesa uterina, diminuindo o potencial da fertilidade na fêmea (Troedsson, 2011). Mattos et al. (2003), ressaltam que as endometrites de uma forma geral, causam relevantes prejuízos na reprodução de equinos por acarretarem baixa fertilidade, morte embrionária e abortos.

Em endometrites fúngicas, os fungos comumente isolados e relatados pela literatura são Candida spp. por Frontoso et al. (2008), assim como os fungos filamentosos dos gêneros Aspergillus, Penicillium, Mucor e Trichosporon (Amaral et al., 2007).

Desta forma, a fim de elucidar a importância de enfermidade reprodutivas como a endometrite e seus agentes etiológicos, objetivou-se caracterizar a citologia e cultura bacteriana e fúngica, além da identificação da formação de biofilme em éguas com suspeita de endometrite.

\section{Material e Método}

\section{Aspectos Éticos e Biossegurança}

Os procedimentos desta pesquisa foram encaminhados para a Comissão de Ética no Uso de Animais (CEUA) da Universidade Federal Rural de Pernambuco, obtendo a licença de número 095/2019.

\section{Coleta de amostras e procedimentos laboratoriais}

Foram examinadas 70 éguas por palpação retal e ultrassonografia após pelo menos 3 inseminações artificiais sem prenhez diagnosticada, ou 3 coletas negativas de transferência de embriões. As amostras foram coletadas para citologia uterina e exame microbiológico. Na coleta, foi utilizado swab coletor estéril acoplado a escova ginecológica (PROVAR $®$ ) para cada animal. Posteriormente, as amostras foram fixadas em metanol por 10 minutos em lâminas com os swabs, sendo acondicionados em tubos contendo meio de transporte (BHI e PBS), imediatamente lacrados, identificados, acondicionados em caixas isotérmicas e encaminhados ao Laboratório de Reprodução Animal (LABRAPE-UFRPE/UAG) para posterior processamento e análise. Animais diagnosticados com citologia positiva foi estabelecido baseado no número de neutrófilos polimorfonucleares (PMN) encontrados nas lâminas coradas por panóptico rápido. Mais de um PMN a cada 10 células epiteliais foram considerados positivos e encaminhados para cultura microbiológica.

\section{Cultura bacteriológica}

A cultura do material foi realizada em placas contendo ágar base acrescido de $8 \%(\mathrm{v} / \mathrm{v})$ de sangue ovino desfibrinado. As placas foram incubadas em aerobiose a $37^{\circ} \mathrm{C}$ por 48 horas, sendo analisadas a cada 24h. Observaram-se as características de crescimento das colônias em placa, como produção de hemólise, pigmento e características morfológicas. Foi confeccionado lâminas pelo método de coloração pela técnica de Gram (Quinn et al., 1994). Para identificação das bactérias foram utilizadas provas bioquímicas relativas à produção de urease, reação em Ágar Tríplice Açúcar Ferro (TSI), teste de VM/VP (VM - reação de Vermelho de Metila; VP - reação de Voges- Proskauer), teste em Ágar SIM (S produção de H2S; I - produção de Indol; M - motilidade) e teste em Ágar Citrato (utilização do carbono do citrato) e teste em meio Simmons. Posteriormente foi realizado a identificação dos patógenos de acordo com a reação ocorridas nos meios acima citados.

\section{Cultura fúngica}

O material foi semeado em 2 placas de ágar Sabouraud com cloranfenicol a 10\%, 2 com ágar seletivo para fungos patogênicos (cloranfenicol e cicloheximida). As placas foram incubadas à temperatura ambiente $\left(25^{\circ} \mathrm{C}\right)$, por até 15 dias, inspecionando-se a cada 24 horas o crescimento fúngico. Após o desenvolvimento de Unidades Formadoras de Colônias (UFC) foi realizada a identificação do 
fungo, sendo a identificação da espécie realizada como descrito por McGinnis (1980).

\section{Formação de Biofilme}

A determinação da formação de biofilme foi feita através de métodos visuais e espectrofotométricos pela técnica de cristal violeta descrita por Stepanovic et al. (2000). O caldo utilizado foi o Sabouraud dextrose (SBD) suplementado com $60 \mathrm{~g}$ de glicose por litro (concentração final de glicose, $80 \mathrm{~g} /$ litro ou $8 \%$ ). Organismos foram cultivados por $24 \mathrm{~h}$ a $35^{\circ} \mathrm{C}$. Utilizou-se uma cepa ATCC como controles em cada teste. A turbidez de cada suspensão foi ajustada para o equivalente de $3 \times 10^{7}$ CFU / ml com SDB, por leituras espectrofotométricas. Sendo inoculado a suspensão em tubo Falcon contendo $9 \mathrm{ml}$ de Agar Sabourand. Posteriormente cada poço de placas de microtitulação foi inoculado com alíquotas de $20 \mu 1$ de suspensão de levedura e $180 \mu 1$ de SDB. O material foi incubado a $35^{\circ} \mathrm{C}$ durante 24 h sem agitação. Observando que todos os isolados de Cândida testados cresceram bem neste meio. Nas placas de microtitulação, os isolados de Cândida cultivados em Sabourand tiveram valores $>1,0$ às $24 \mathrm{~h}$ para todas as espécies com um inóculo inicial de $10^{6} \mathrm{CFU} / \mathrm{ml}$. Após $24 \mathrm{~h}$ de incubação, o caldo foi retirado por aspiração e os tubos foram lavados uma vez com água destilada. As células de meios e leveduras foram descartadas. O biofilme que ficou aderido foi classificado como negativa, fraco $(1+)$, moderado $(2++$ ou $3+++)$, ou fortemente $(4++++)$ como é classificado por Pfaller et al. (2002). Cada isolado foi avaliado em triplicata de dias diferentes. As leituras espectrofotométricas foram realizadas a $405 \mathrm{~nm}$ com leitor de placa de microtitulação, Como a porcentagem de transmitância (\% T) estava sendo medida, um comprimento de onda de $405 \mathrm{~nm}$ foi seleccionado para leitura das placas para minimizar a absorbância. O valor de \% de Transmitância para cada amostra de teste foi subtraído do valor de \% T para o reagente em branco para obter uma medida da quantidade de luz bloqueada ao passar pelos poços ( $\% \mathrm{~T}$ bloc). A produção de biofilme de cada isolado foi classificada como negativo (\% T bloc, 5), 1 ( $\%$ T bloc, 5 a 20), 2 (\% T bloc, 20 a 35), 3 (\% T bloc, 35 a 50), ou 4 (\% T bloc, 50). Cada isolado foi testado pelo menos duas vezes. Nenhuma grande discrepância ocorreu entre os resultados obtidos pelo método de leitura visual e aqueles obtidos pelo método espectrofotométrico.

\section{Análise estatística}

Empregou-se a técnica de estatística descritiva por meio da distribuição das frequências relativa e absoluta para os achados microbiológicos e fúngicos, identificação dos agentes assim como para a formação de biofilme.

\section{Resultados e Discussão}

Das 70 éguas diagnosticadas com endometrite $43(61,4 \%)$ apresentaram infecção bacteriana e/ou fúngica. Dessas, 30,2\% (13/43) apresentaram infecção fúngica, e dentre os fungos mais evidenciados foram encontrado o Aspergillus spp. e Candida albicans, que são descritos como agentes altamente virulentos e formadores de biofilme, seguido de Curvalaria spp., Cladosporium spp. e Zygomices spp. característico como contaminantes ambientais (Tongu et al., 2015). Dos fungos identificados, 9/13 $(69,2 \%)$ formaram biofilme e foram observados alguns microrganismos (Tab. 1).

A infecção fúngica nas éguas, podem estar relacionadas com diversos fatores, dentre eles uma maior exposição das fêmeas à colonização fúngica em decorrência da intensa manipulação do trato reprodutivo, uso prolongado de hormônios (progesterona e corticoides), enfermidades cervicais e contaminação fecal. Estas possibilidades já foram descritas pela literatura por vários autores (Alvarenga, 2008; Liu e Troedsson, 2008). Outro fator predisponente é a associação da enfermidade com antibioticoterapia uterina, pneumovagina/urovagina e grande quantidade de fluido intrauterino, como relatado por Stout (2008).

Segundo Fumuso et al. (2007), uma grande parte das endometrites de origem fúngica tem caráter crônico, o que na maioria das vezes é diagnosticado em animais que apresentam endometrites persistentes. Tal cronicidade pode sugerir que algumas metodologias das biotecnologias da reprodução, assim como tratamentos e outras enfermidades atuem diminuindo a capacidade de eliminação dos agentes do ambiente uterino e predispondo-o a persistência. Porém, Petrites-Murphy et al. (1996) afirmam que alguns casos podem ser de caráter agudos em decorrência de abortos com etiologia micótica.

Os resultados encontrados, mostram uma maior identificação e participação da Candida albicans, estando de acordo com a literatura em animais com endometrites fúngicas, como descritos por 
Amaral et al. (2007) Frontoso et al. (2008) Liu e Troedson (2008), fato justificado pela presença naturalmente no trato reprodutivo animal por este grupo de microrganismos. Scofield et al. (2013), afirmam que os principais agentes em endometrites fúngicas são Candida spp., Aspergillus spp. e Mucor spp. Em ordem de importância, a Candida albicans é considerada o agente que mais acomete o trato reprodutivo da égua (Petrites-Murphy et al., 1996), seguido em segundo lugar pelos agentes do gênero Aspergillus spp., estes agentes por sua vez são capazes de produzir e liberar enzimas (elastase) e provocar uma infecção mais profunda por penetrar nos tecidos (Alvarenga, 2008).

Tabela 1. Microrganismos encontrados e a produção de biofilme das 70 éguas.

\begin{tabular}{c|c}
\hline Microrganismo & Produção de Biofilme \\
\hline Aspergillus spp. & $\mathrm{Neg}$ \\
\hline C. albicans & $\mathrm{P}+++$ \\
\hline Zygomices spp. & $\mathrm{P}+++$ \\
\hline Aspergillus spp. & $\mathrm{P}++$ \\
\hline Curvalaria spp. & $\mathrm{Neg}$ \\
\hline Curvalaria spp. & $\mathrm{Neg}$ \\
\hline Nidentificado & $\mathrm{Neg}$ \\
\hline C. albicans & $\mathrm{P}+++$ \\
\hline C. albicans & $\mathrm{P}++++$ \\
\hline Curvalaria $s p p$. & $\mathrm{P}+$ \\
\hline$C$. albicans & $\mathrm{P}++++$ \\
\hline C. albicans & $\mathrm{P}++++$ \\
\hline Aspergillus $s p p$. & $\mathrm{P}++++$ \\
\hline
\end{tabular}

Neg (Negativo); P(positivo), fraco (1+), moderado (2++ ou 3+++), ou fortemente (4++++).

Embora haja a possibilidade de serem encontrados todas as espécies de fungos no trato reprodutor de éguas. Os mais comumente identificados em quadros de endometrites são os do gênero Candida spp. e Aspergillus spp. segundo Tongu (2015). Os microrganismos Curvalaria spp., Cladosporium spp. e Zygomices spp. foram identificados no presente trabalho possivelmente decorrente de contaminações ambientais. Tais microrganismos são agentes rotineiramente associados a dermatites fúngicas, no caso da Curvalaria spp. (Hiromoto et al., 2008), encontrados como contaminantes e agentes de deterioração em alimentos, produtos industriais, solo, pedras, tijolos, papel e couro no caso do Cladosporium spp. (Gutarowska, 2014) e danos traumáticos ao tecido ou supressão do sistema imunológico, como o Zygomices spp. O que nos leva a hipotetizar que houve uma redução da resposta imunológica do animal levando ao aparecimento dessas espécies oportunistas.

Ribas et al. (2014) ao avaliarem 85 éguas, encontraram apenas cinco animais com endometrite fúngica, o que corresponde a 5,9\% dos casos. Este resultado é bem inferior ao encontrado no presente estudo $[30,2 \%(13 / 43)]$. A porcentagem de endometrites relatadas por alguns trabalhos na literatura variam de 2,0 a 13,5\% por Collins (1964), Dascanio et al. (2001), Amaral et al. (2007), Riddle et al. (2007) e Frontoso et al. (2008). Estas variações podem sugerir que endometrites fúngicas ocorrem com mais frequência em regiões tropicais (Lacaz et al., 1984), fato atribuído principalmente ao ambiente e demais condições mais propícias ao desenvolvimento micótico (Carter e Chenpaga, 1995). Em virtude de poucos dados relacionados a este tipo de endometrites nas regiões tropicais, não se pode efetivamente confirmar tal fato.

É importante frisar que em todos os casos aqui relatados os animais apresentaram queixa de subfertilidade com diagnóstico gestacional negativo após 3 inseminações artificiais ou 3 coletas negativas de transferência de embriões. Para tal, o diagnóstico de endometrite foi efetuado visando esclarecer de fato a presença ou não de endometrite. Além disso, as biotecnologias utilizadas em parte envolveram a participação hormonal, e neste quesito, no caso das receptoras de embriões, houve utilização da progesterona (Altrenogest ${ }^{\circledR}$ ) no momento da colocação do embrião sendo interrompido o tratamento após o diagnóstico negativo de prenhez. Este hormônio, reduz a capacidade de identificação leucocitária e consequentemente a fagocitose e lise dos agentes patogênicos, o que predispõe as infecções fúngicas 
(Troedsson, 2011).

A porcentagem encontrada em maior quantidade neste estudo pode ser explicada por duas vertentes, a primeira sugere uma maior exposição dos animais a esporos dos fungos, o que já foi relatado por Carter e Chenpaga (1995), como um importante fator predisponente para a endometrite micótica e persistência dos animais com tal enfermidade, já que o desenvolvimento fúngico pode ocorrer em todo o ano em países tropicais. A segunda, sugere um maior e melhor identificação e controle das condições laboratoriais para a cultura e isolamento, já que segundo Amaral et al. (2007), vários problemas no diagnóstico de endometrites fúngicas são atrelados a falhas ou problemas com a cultura e o isolamento do fungo. Ribas et al. (2014), reiteram que para um diagnóstico preciso, devem-se utilizar meios específicos para o crescimento fúngico, e aguardar um período mais longo de avaliação, já que este crescimento é mais lento.

No que se refere a formação de biofilme, Carneiro et al. (2018) considera a formação de biofilme no trato reprodutivo equino como uma causa significativa de endometrite crônica na égua. Os agentes encontrados no presente estudo como a Candida albicans e Aspergillus spp. são considerados como formadores de biofilme por dificultar a limpeza uterina devido ao aumento da adesão às superfícies epiteliais, o que de acordo com Buczkowska et al. (2015), impede a remoção física e estimula a produção de exsudato inflamatório. Alvarenga (2008) acrescenta que a formação do biofilme interfere diretamente nos mecanismos imunológicos de defesa do útero, aumentando ainda mais a resistência dos agentes a eliminação uterina.

A formação de biofilme e identificação de agentes em éguas com endometrites já foram descritas por Zhang (2012) com Cladosporium sphaerospermum, Siqueira e Lima (2013) por Aspergillus spp., Botrytis spp., Alternaria spp., Cladosporium spp. e Carneiro et al. (2019) por Aspergillus spp., corroborando com os achados no presente estudo e evidenciando a participação do Aspergillus ssp. como um dos principais agentes.

De uma forma geral, a formação de biofilmes, torna os microrganismos resistentes a conduta terapêutica e consequentemente pode ocasionar infecções crônicas (Leblanc, 2010). Vários são os métodos para sobreviver à degradação ou tentativa de eliminação pelo sistema imunológico do hospedeiro e pela antibioticoterapia. Os biofilmes permitem que os microrganismos não sejam reconhecidos pelo sistema imunológico, impedem a exposição a antibióticos e permitem à resistência a antibioticoterapia pela troca de material genético (Donlan e Costerton 2002).

\section{Conclusão}

As endometrites de uma forma geral, são enfermidades muito importantes para o agronegócio equino, quer seja de origem bacteriana ou fúngica. $\mathrm{O}$ seu diagnóstico torna-se imprescindível, porém muitas vezes complexo e consequentemente agravante para a resolução do quadro clínico, tornando-o crônico e comprometendo a vida produtiva e reprodutiva do animal. A caracterização, identificação do agente associada a formação de biofilme são metodologias fundamentais no diagnóstico e terapia de tais enfermidades. Pôde-se identificar os agentes Aspergillus spp. e Candida albicans, Curvalaria spp., Cladosporium spp. e Zygomices spp. em animais com endometrite fúngica. Além disso, os fungos isolados demonstram uma necessidade em melhorias nas biotecnologias da reprodução, bem como os devidos cuidados assépticos destas ações.

\section{Referências}

Alvarenga MA. Diagnóstico e tratamento de endometrite fúngica em éguas. In: IX CONFERÊNCIA ANUAL DA ABRAVEQ, 2008. São Paulo, Brasil. Anais... São Paulo. 2008.

Amaral MG, Pimentel CA, Meireles M, Fiala SM, Schramm R, Xavier EG, Mendonça M. Endometrite eqüina. Fungos e bactérias. Arch Zootec, v.216, p.875-884, 2007.

Buczkowska J, Kozdrowski R, Sikora M, Dzieciol M, Matusz A. Non-traditional treatments for endometritis in mares. Bulg. J Vet Med, v.17, n.4, p.285-293, 2015.

Carter GR, Chengappa MM. Introduction to de fungi and fungous infeccion. In: Carter, GR.; Chengappa, MM; Roberts, GHC.; Rikihisa, Y. (Eds), Essentials of Veterinary Microbiology. Philadelphia: Williams and Wilkins, p.251-256, 1995.

Collins SM. Study of incidence of cervical uterine infections in Thoroughbred mares in Ireland. Vet Rec, v.66, p.673-676, 1964.

Dascanio JJ, Schweizer C, Ley W. Equine fungal endometritis. Equine Vet Educ, v.13, n.6, p.324-329, 
2001.

Donlan RM, Costerton JW. Biofilms: Survival mechanisms of clinically relevant microorganisms. Clin Microbiol Rev, v.15, p.167-193, 2002.

Frontoso R, de Carlo E, Pasolini MP, Van Der Meulen K, Pagnini U, Iovane G, De Martino L. Retrospective study of bacterial isolates and their antimicrobial susceptibilities in equine uteri during fertility problems. Res Vet Sci, v.84, p.1-6, 2008.

Fumuso EA, Aguilar J, Giguère S, Rivulgo M, Wade J, Rogan D. Immune parameters in mares resistant and susceptible to persistent post-breeding endometritis: Effects of immunomodulation. Vet Immunol Immunopathol, v.1, p.830-39, 2007.

Gutarowska, B. Moulds in biodeterioration of technical materials. Folia Biologica et Oecologica, v.10, n.1, p.27-39, 2014

Hiromoto A, Nagano T, Nishigori C. Cutaneous infection caused by Curvularia species in an immunocompetent patient. Br J Dermatol, v.158, n.6, p.1374-1375, 2008.

Lacaz CS, Porto E, Martins JEC. Micologia Médica: Fungos actinomicetos e algas de interesse médico. 7. ed. São Paulo: Sarvier, p.479, 1984.

Leblanc MM. Advances in the Diagnosis and Treatment of Chronic Infectious and Post-Mating-Induced Endometritis in the Mare. Reprod Domest Anim, Berlin, v.45, n.2, p.21-27, 2010.

Liu KM, Troedsson MHT. The diagnosis and treatment of endometritis in the mare: Yesterday and today. Theriogenology, v.70, p.415-420, 2008.

Mattos RC, Malschitzky E, Jobim MIM. Endometrite na égua. Rev Bras Reprod Anim, v.27, n.2, p.150-157, 2003.

McGinnis MR. Laboratory Handbook of Medical Mycology. New York: Academic Press; p.133-136, 1980.

Nascimento Júnior JAA, Correia MTS, Carneiro GF. Identificação fúngica e formação de biofilme provenientes de amostras endometriais de éguas. Rev Bras Reprod Anim, v.43, n.2, p.601, 2019.

Petrites-Murphy MB, Robbins LA, Donahue JM, Smith B. Equine cryptococcal endometritis and placentitis with neonatal cryptococcal pneumonia. J Vet Diagn Invest., v.8, p.383-386, 1996.

Pfaller MA, Diekema DJ, Jones RN, Messer SA, Hollis RJ. Trends in antifungal susceptibility of Candida spp. isolated from pediatric and adult patients with bloodstream infections: SENTRY antimicrobial surveillance program,1997 to 2000. J Clin Microbiol, v.40, p.852-856, 2002.

Quinn, PJ, Carter ME, Carter GR. Clinical Veterinary Microbiology, London: Wolfe, p.648, 1994.

Ribas JA, Carvalho EQ, Stussi JP. Endometrite fúngica em éguas: diagnóstico e implicações clínicopatológicas. $R$ Bras Ci Vet, v.21, n.3, p.204-212, 2014

Riddle WT, Leblanc MM, Stromberg AJ. Relationships between uterine culture, cytology and pregnancy rates in a Thoroughbred practice. Theriogenology, v.68, p.395-402, 2007.

Scofield DB, Wittenburg LA, Ferris RA, Gustafson DL, Mccue PM. Equine endometrial tissue concentration of fluconazole following oral administration. J Equine Vet Sci, v.33, p.44-50, 2013.

Siqueira VM, Lima N. Biofilm formation by filamentous fungi recovered from a water system. Journal of Mycology, v.2013, p.1-9, 2013.

Stepanovic S., Vukovic D, Dakic I, Savic B, Svabic-Vlahovic M. A modified microtiter-pate test for quantification of staphylococcal biofilm formation. J Microbiol Methods. v.40, p.175-179, 2000.

Stout TAE. Fungal endometrites in the mare. Pferdeheikunde, v.24, p.83-87, 2008.

Tongu EAO, Taborda CP, Marques SAV, Gomes GM, Gomes LPM, Peixoto Jr. KC, Crespilho AM. Sensibilidade do Laminocultivo Dermatobac ${ }^{\circledR}$ para o diagnóstico da Endometrite Fúngica em Éguas. Ciênc Anim Bras, v.16, n.4, p.598-607, 2015.

Traub-Dargatz JL, Salman MD, Voss JL. Medical problems of adult horses, as ranked by equine practitioners. JAVMA, v.198, p.1745-1747, 1991.

Troedsson MHT. Endometritis. In: MCKINNON, A. O. (Ed.) Equine Reproduction. Philadelphia: Wiley- Blackwell, cap.271, p.2608-2619, 2011.

Vargas H, Nascimento Júnior JAA, de Sobral GG, Viana AR, Vilar IJ, Carneiro GF. Intrauterine Infusion of Ozone in susceptible mare. Anim Reprod, v.16, n.1, p.103, 2019.

Wittenbrink MM. Bacterial infections of the equine genital tract. Pferdeheilkunde, v.28, p.30-32, 2012.

Zhang X, Sun X, Wan Z, Zhang Y, Hou W. Keratitis-associated fungi form biofilms with reduced antifungal drug susceptibility. IOVS, v.53, n.12, 2012. 